25(6), 877-887

\title{
Introduction of Chain-Weighted Method and GDP Fluctuations
}

\author{
In Gyu Lee ${ }^{1} \cdot$ Chun Il Park² \\ ${ }^{1}$ Economic Statistics Department, The Bank of Korea \\ ${ }^{2}$ Department of Economics, Yonsei University
}

(Received September 6, 2012; Revised October 10, 2012; Accepted October 22, 2012)

\begin{abstract}
The Bank of Korea changed its method of GDP estimation from a fixed-weighted to a chain-weighted measure in 2009. The fixed-weighted method had had problems such as substitution bias and the rewriting of economic history. As a result of the change, annual growth rates calculated using the chain-weighted method from 1970 through 2008 turned out to be $0.8 \%$ p higher on average than the existing rates. The quarterly average chain-weighted growth rates were $0.19 \% \mathrm{p}$ higher than the fixed-weighted ones, but they changed in the same directions. In this paper we analyze whether the differences in rates between the two calculation methods would bring about a difference in the cyclical characteristics of GDP. We conclude that although there were differences in growth rates after introduction of the chain-weighted method, there was no difference in the cyclical fluctuation.
\end{abstract}

Keywords: Chain-weighted GDP, trend, cycle, co-movement.

\section{1. 서론}

한국은행은 2009 년에 국민소득통계의 2005년 기준년을 개편하면서 경제성장률 추계방식을 UN이 발 간한'1993 SNA'의 권고에 따라 기존의 고정가중법(fixed-weighted method)에서 연쇄가중법(chainweighted method)으로 전환하였다. 고정가중법은 가중치 기준년을 매5년마다 변경함에 따라 상대가 격체계의 변화를 제때에 반영하지 못하는 '대체편의'(substitution bias)의 문제점을 내포하고 있다. 그 리고 기준년개편시 마다 전구간의 경제성장률이 모두 바뀌는 이른바 '과거시계열 전면재수정'(rewriting of economic history) 문제점을 안고 있었으나 연쇄가중법 도입으로 이와 같은 두 가지 문제점이 해결 되었다. 한편 연쇄가중법 도입으로 경제성장률이 1970 1999년 중에는 기존의 고정가중 경제성장률보 다 높게 나타난 반면 2000 2008년 중에는 낮게 나타났으며 개편대상기간 전체로는 연평균 $0.8 \% \mathrm{p}$ 높게 나타났다. 정책당국자 등 통계이용자의 입장에서는 이와 같은 경제성장률의 차이가 유의한 것인지 그리 고 경제의 순환변동에 차이를 가져오는지를 알아볼 필요가 있다. 연쇄가중법을 세계 최초로 도입한 미 국의 경우 도입 당시 경제성장률이 크게 하향 조정되면서 상당한 혼란을 가져왔고 이 같은 조정이 경기 순환 판단에 영향을 미치는지 여부에 대한 연구가 활발하였다. Young (1993)은 미국의 실질GDP 순환

\footnotetext{
${ }^{1}$ Corresponding author: Economic Statistics Department, The Bank of Korea, 110, 3-Ga, Namdaemunno, Jung-Gu, Seoul 100-794, Korea. E-mail: iglee@bok.or.kr
} 
Table 2.1. Formulas for calculating alternative measures

\begin{tabular}{|c|c|c|c|}
\hline & \multicolumn{2}{|c|}{ Fixed-weighted Method } & Chain-weighted Method \\
\hline $\begin{array}{l}\text { Quantity Index } \\
\text { (Laspeyres Index) }\end{array}$ & $\begin{aligned} Q_{(0, t)}^{L} & =\sum w_{0} \frac{q_{t}}{q_{0}} \\
& =\frac{\sum p_{0} q_{t}}{\sum p_{0} q_{0}}\end{aligned}$ & & $\begin{array}{l}Q_{(0, t)}^{L C}=Q_{(0,1)}^{L} \times Q_{(1,2)}^{L} \times \cdots \times Q_{(t-1, t)}^{L} \\
\text { 단, } Q_{(t-1, t)}^{L}=\sum w_{t-1} \frac{q_{t}}{q_{t-1}}=\frac{\sum p_{t-1} q_{t}}{\sum p_{t-1} q_{t-1}} \\
\left(Q_{(0, t)}^{L C} \text { is Chain index, } Q_{(t-1, t)}^{L} \text { is Link Index }\right)\end{array}$ \\
\hline Weight & $w_{0}=\frac{p_{0} q_{0}}{\sum p_{0} q_{0}}(\mathrm{~F}$ & ixed) & $w_{t-1}=\frac{p_{t-1} q_{t-1}}{\sum p_{t-1} q_{t-1}}($ Yearly changed $)$ \\
\hline $\begin{array}{l}\text { Real GDP } \\
\text { (Volume) }\end{array}$ & $\begin{aligned} \mathrm{GDP}_{t} & =\sum p_{0} q_{0} \\
& =\sum p_{0} q_{0} \\
& =\sum p_{0} q_{t}\end{aligned}$ & $\begin{array}{l}\times Q_{(0, t)}^{L} \\
\times \sum^{w_{0}} \frac{q_{t}}{q_{0}}\end{array}$ & $\begin{aligned} \mathrm{GDP}_{t} & =\sum p_{0} q_{0} \times Q_{(0, t)}^{L C} \\
& =\sum p_{0} q_{0} \times Q_{(0,1)}^{L} \times Q_{(1,2)}^{L} \times \cdots \times Q_{(t-1, t)}^{L} \\
& =\sum p_{0} q_{0} \times \sum w_{0} \frac{q_{1}}{q_{0}} \times \cdots \times \sum w_{t-1} \frac{q_{t}}{q_{t-1}}\end{aligned}$ \\
\hline Growth Rate (\%) & $\begin{array}{l}{\left[\frac{\sum p_{0} q_{t}}{\sum p_{0} q_{t-1}}-1\right]} \\
=\left[\frac{Q_{(0, t)}^{L}}{Q_{(0, t-1)}^{L}}-1\right]\end{array}$ & $\times 100$ & $\begin{array}{l}{\left[\frac{\text { Chain } \mathrm{GDP}_{t}}{\text { Fixed GDP }_{t-1}}-1\right] \times 100} \\
=\left[\frac{Q_{(0, t)}^{L C}}{Q_{(0, t-1)}^{L C}}-1\right] \times 100 \\
=\left(Q_{(t-1, t)}^{L}-1\right) \times 100\end{array}$ \\
\hline
\end{tabular}

주기를 분석한 결과 GDP의 정점과 저점을 나타내는 시기는 두 방법상 차이가 없다는 사실을 밝혀냈다. Parker와 Seskin (1996)은 고정GDP에 의할 경우 80.2/4분기 1분기의 수축을 보였으나 연쇄GDP의 경 우 80.2/4 3/4분기 중 2 분기 연속 수축이 있었다는 차이를 밝히고 있다. Pakko (1997)는 미국의 경우 연쇄 $\mathrm{GDP}$ 의 순환변동치와 $\mathrm{NBER}$ 의 공식적인 경기순환주기 간에는 아주 밀접한 관계가 있고 방법의 변 경에도 불구하고 GDP순환변동치는 거의 영향을 받지 않는 것으로 주장하고 있다. Steindel (1995)은 연쇄가중법 도입으로 잠재성장률이 조금 낮아지나 단기적인 거시경제 정책분석에 거의 영향을 미치지 않는 것으로 분석하고 있다. 따라서 본 논문에서는 우리나라의 경우 연쇄가중 경제성장률과 기존의 고 정가중 경제성장률간 경기적 특성에 차이가 있는지를 분석해 보고자 한다.

\section{2. 연쇄가중 경제성장률 도입결과}

\section{1. 우리나라의 연쇄가중 경제성장률 도입 배경}

고정지수는 특정년도(기준년)의 상대가격에 의하여 산출된 고정된 가중치를 사용하여 떨어져 있는 두 기간의 물량변동을 직접 측정하는 반면, 연쇄지수는 매년 직전년도의 가중치를 사용하여 인접년도의 물 량(연환지수)을 측정하고 이를 누적하여 떨어져 있는 두 기간의 전체 변동을 간접적으로 측정하는 방법 이다 (Table 2.1). 실질GDP금액은 고정과 연쇄 방법 모두 기준년 GDP에 물량지수를 곱하여 산출하고 이를 이용하여 경제성장률을 산출한다. 연쇄가중법에 의한 경제성장률 산출과정에 대한 자세한 내용은 Bank of Korea (2009)을 참고할 수 있다.

우리나라에서 연쇄가중 경제성장률을 도입하게 된 배경은 첫째로 반도체 휴대폰 등 정보통신산업 제품 의 급속한 성장이다. 정보통신산업의 실질 GDP 비중은 1996 년 $3.9 \%$ 에서 2007 년 $15.0 \%$ 로 확대되고 $\mathrm{PC}$ 가격지수는 1996년 194.7에서 2007년도에는 16.5로 하락하였다 (Table 2.2).

이와 같이 물량은 급증하고 가격은 급락하는 경우 가중치변화를 즉시 반영할 수 없어 고정가중법에서는 경제성장률이 과대 계상되는 '대체편의'가 크게 발생하게 된다. Deaton과 Muellbauer (1980)는 연쇄 
Table 2.2. Proportion of IT in fixed-weighted GDP

\begin{tabular}{|c|c|c|c|c|c|}
\hline & 1996 & 2000 & 2005 & 2006 & 2007 \\
\hline $\begin{array}{c}\text { GDP Growth Rate } \\
\text { IT Growth Rate }\end{array}$ & $-\frac{7.0}{16.8}$ & $-\frac{8.5}{33.8}$ & $-\frac{4.2}{13} \cdot \overline{5}$ & $\frac{5.1}{13} \cdot \overline{5}$ & $-\frac{5.0}{9.5}--$ \\
\hline Contribution to Growth & 0.6 & 2.3 & 1.7 & 1.8 & 1.4 \\
\hline 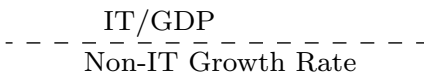 & $-\frac{3.9}{6 .} \frac{1}{6}$ & $-\frac{8.4}{6.6}$ & $-\frac{13.4}{2.9}$ & $-\frac{14.4}{3.8}$ & $\frac{15.0}{4.2}--$ \\
\hline PC Price index & 194.7 & 100.0 & 24.3 & 19.1 & 16.5 \\
\hline
\end{tabular}

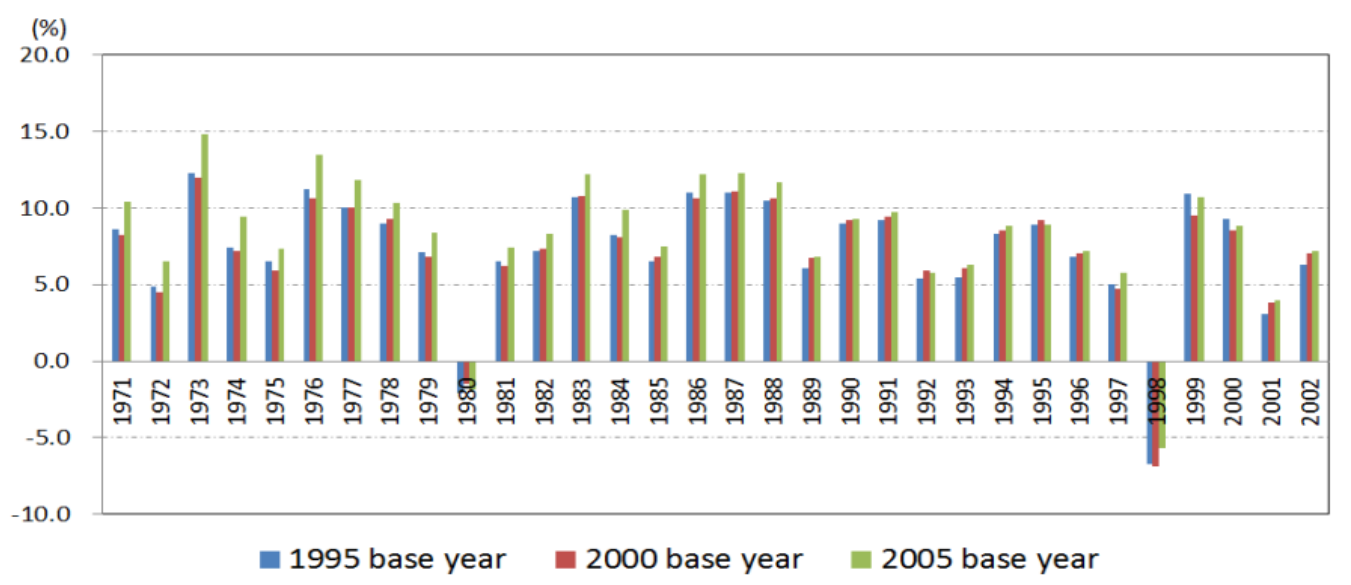

Figure 2.1. Changes in growth rate due to base year revisions

Table 2.3. Comparison of annual GDP growth rates

\begin{tabular}{lccccc}
\hline & $1971 \sim 1979$ & $1980 \sim 1989$ & $1990 \sim 1999$ & $2000 \sim 2008$ & $1971 \sim 2008$ \\
\hline Chain-weighted (A) & 10.2 & 8.5 & 6.6 & 4.8 & 7.5 \\
Fixed-weighted (B) & 8.3 & 7.6 & 6.1 & 4.9 & 6.7 \\
\hline Difference (A - B) & 1.9 & 0.9 & 0.5 & -0.1 & 0.8 \\
\hline
\end{tabular}

가중 경제성장률이 대체편의를 제거해주는 과정을 이론적으로 설명해주고 있다. 둘째로 고정가중법 사 용으로 1970 년 이후 매5년마다 기준년 개편 작업이 있었는데 그때마다 과거 경제성장률이 모두 변경되 는 이른바 '과거시계열 전면재수정' 문제를 가지고 있다 (Figure 2.1). 과거시계열이 5년 주기로 전면 재수정되는 것은 통계작성자나 이용자에게 당혹스러운 일이다. 연쇄가중경제성장률은 과거시계열이 재 수정되는 문제가 발생하지 않는다.

셋째로 국제비교가능성을 제고하기 위함이다. 현재 대부분의 OECD 회원국은 UN이 $1993 \mathrm{SNA}$ 에서 권고하고 있는 연쇄가중 경제성장률을 작성공표하고 있다.

\section{2. 연쇄가중 경제성장률 작성결과}

연쇄가중 경제성장률은 1971 년 2008년 중 연평균 $7.5 \%$ 로 나타나 고정가중 경제성장률 $6.7 \%$ 보다 $0.8 \%$ 높게 나타나고 있다 (Table 2.3). 이를 구간별로 나누어 보면 1970 년대에는 $10.2 \%$ 로 $1.9 \% \mathrm{p}$ 높 게 나타났으며 1980 년대에는 $0.9 \% \mathrm{p}, 90$ 년대에는 $0.5 \% \mathrm{p}$ 높게 나타났다. 그러나 2000 년대에는 $0.1 \% \mathrm{p}$ 낮게 나타났는데 이는 연쇄가중법 도입으로 '대체편의'해소 효과와 기준년 개편 효과가 결합되어 나타 


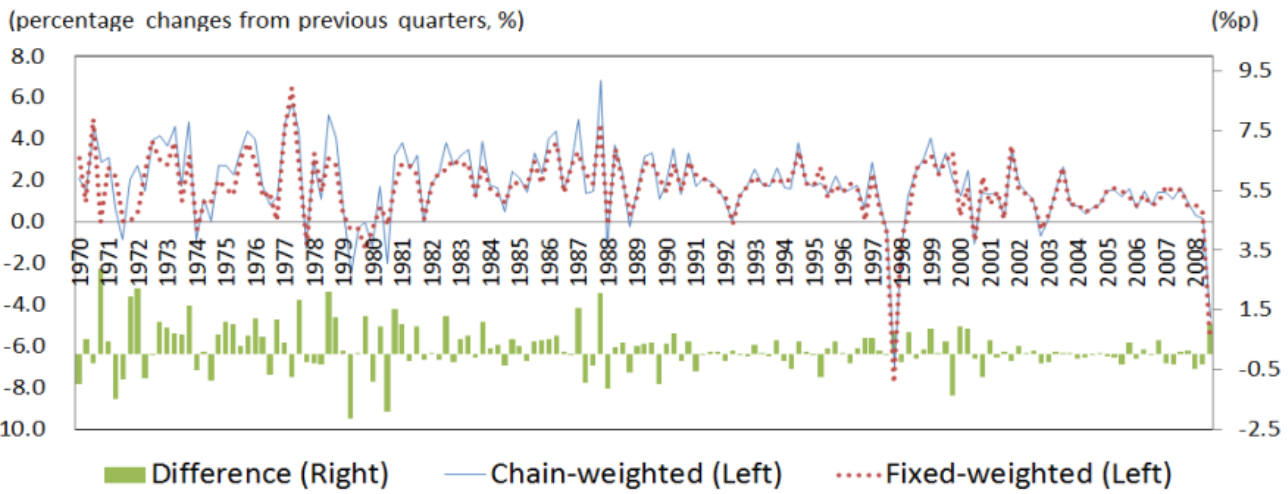

Figure 2.2. Comparison of alternative quarterly growth rates

났기 때문이다.

다음으로 $1970.1 / 4 \sim 2008.4 / 4$ 분기 중 전기비 경제성장률을 비교해 보면 동기간 중 연쇄가중 성장률 $1.80 \%$ 로 고정가중 성장률 $1.61 \%$ 보다 $0.19 \% \mathrm{p}$ 높게 나타났으며 분기별 최대 차이는 $2.9 \% \mathrm{p}$ 를 보이고 있다 (Figure 2.2). 자기상관과 이분산이 존재하는 시계열자료에 대한 Newey와 West (1987)의 분산 을 이용한 $t$-hac 검정결과 $t$-hac값이 3.98 로 $t_{0.025}=1.98$ 보다 크므로 두 개의 평균에는 $5 \%$ 유의수 준에서 유의한 차이가 있는 것으로 나타났다. 여기서 $t$-hac $=\bar{R} / \sqrt{\widehat{\operatorname{VAR}}(\bar{R})}, R$ 은 두 자료간 차이이 며 $\widehat{\operatorname{VAR}}(\bar{R})=1 /\{n(n-1)\} \cdot\left\{\sum_{t=1}^{n} \hat{\epsilon}_{t}^{2}+2 \sum_{v=1}^{q}\left((1-v /(q+1)) \sum_{t=v+1}^{n} \hat{\epsilon}_{t} \hat{\epsilon}_{t-v}\right)\right\}, \hat{\epsilon}_{t}=R_{t}-\bar{R}$ 이 다. $q$ 는 자기상관이 존재하는 절단시차(truncation lag)로 $\left[0.75 n^{1 / 3}\right]$ 을 사용하였다. $t$-hac의 자유도는 $n-1$ 이 되므로 $t$-hac통계량의 절대값이 $t_{\alpha / 2}(n-1)$ 보다 클 때 유의수준 $\alpha$ 에서 두 개의 평균이 유의 하게 다르다는 결론을 내린다. 한편 PT검정 (Pesaran과 Timmerman, 1992)에 의해 두 통계간 증감방 향 $(+,-)$ 의 일치여부 검정결과 검정통계량 $S_{n}^{2}$ 는 $98.18(p$-값: 0.000$)$ 으로 고정과 연쇄가중법에 의한 전 기비 증감방향에는 유의한 차이가 없는 것으로 나타났다. 여기서 $S_{n}^{2}=\left\{\left(\hat{p}-p^{*}\right)^{2}\right\} /\left\{V(\hat{p})-V\left(p^{*}\right)\right\}$, $\hat{p}=1 / n \sum_{i=1}^{n} X_{i}, X_{i}$ 는 양 계열의 증감방향이 같은 경우 1 , 다를 때는 0 의 값을 가지는 이항변수이다. 동 검정법은 증감방향이 서로 독립이라는 귀무가설을 검정한다. $p$ 는 양 성장률의 변동방향이 일치하는 비율을 나타내며, $p^{*}$ 는 양통계가 서로 독립이라는 가정 하에서 $p$ 의 기댓값이며, $V(\hat{p}), V\left(p^{*}\right)$ 는 각각 $\hat{p}$, $p^{*}$ 의 분산을 나타낸다.

다음으로 GDP 구성항목에 대한 수준을 살펴보면 1970.1/4 2008.4/4분기 중 주요 4개 경제활동별 부 가가치를 보면 농림어업과 서비스업은 연쇄 GDP가 고정 GDP보다 수준이 높게 나타나는 반면 건설업은 이와 반대로 낮게 나타나고 제조업은 비슷하게 나타난다. 6 개 지출항목에서는 민간소비만이 연쇄가 고 정보다 낮을 뿐 여타 지출항목은 비슷하게 나타나고 있다 (Figure 2.3). 한편 10개 구성항목에 대해 두 방법에 의한 성장률의 평균이 동일하다는 귀무가설 하에 $t$-hac검정을 실시한 결과 $t$-hac값이 서비스업 은 6.15 민간소비는 3.68 로 나타나 $t_{0.025}=1.98$ 보다 크므로 $5 \%$ 유의수준에서 유의한 차이가 있는 것으 로 나타났다. 나머지 8 개 항목은 유의한 차이는 없는 것으로 나타났다.

\section{GDP의 경기순환행태 검정}

\subsection{GDP 순환변동치 추출방법}

각 경제지표의 변동은 그 자체의 고유한 특징을 가지고 있는데 특정한 규칙성들이 경제변동의 일반적 
(Economic Activity, $1970=1)$
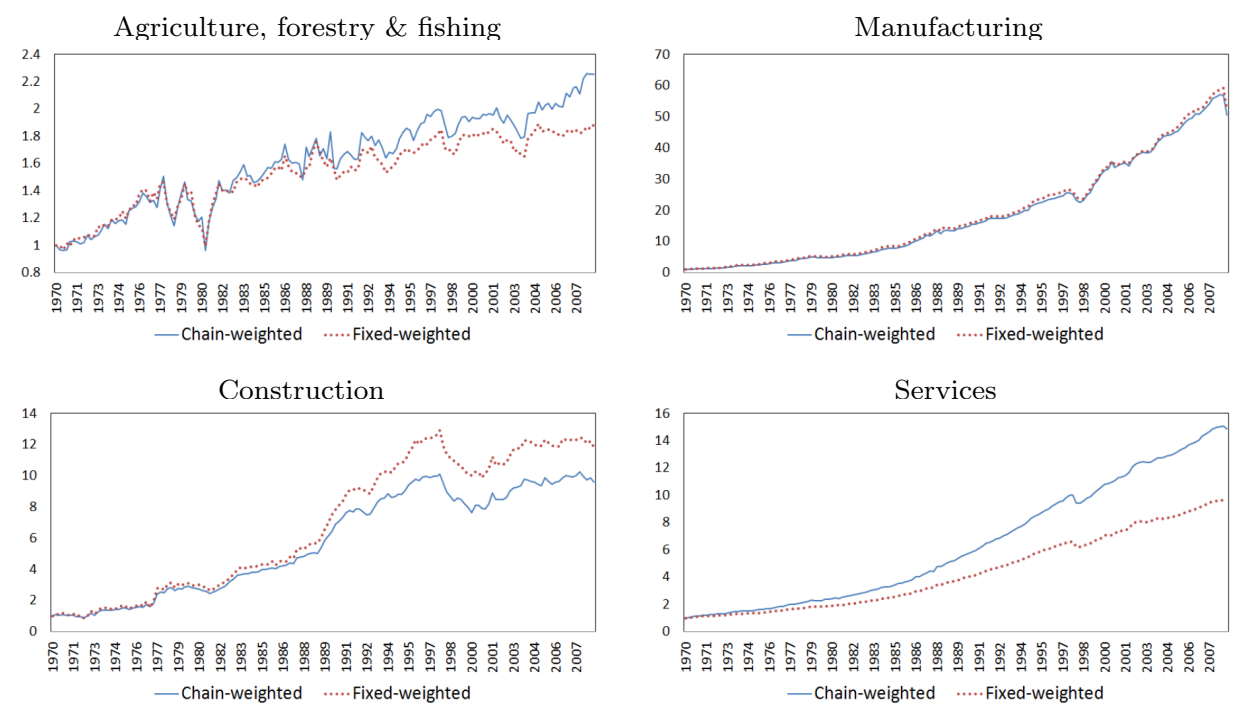

$($ Expenditure, $1970=1)$

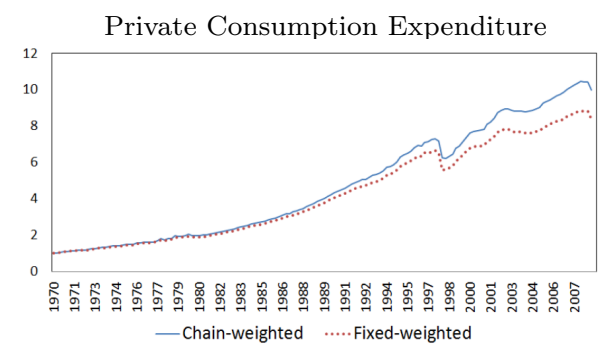

Government Consumption Expenditure
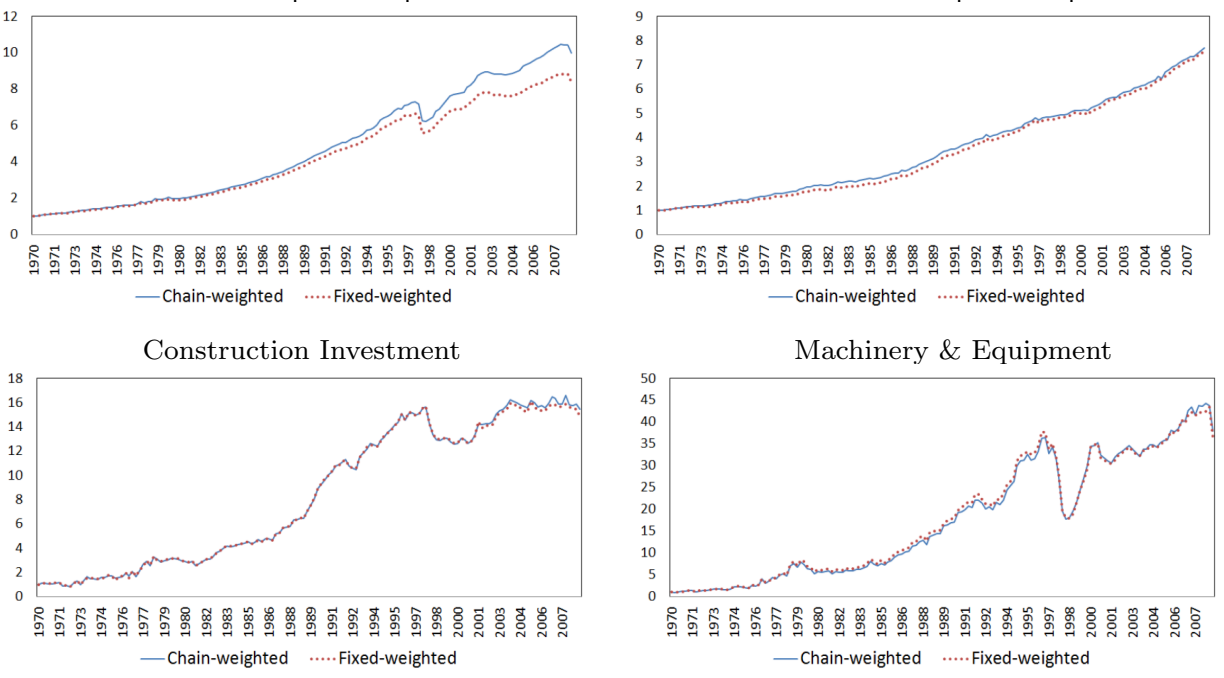

Exports
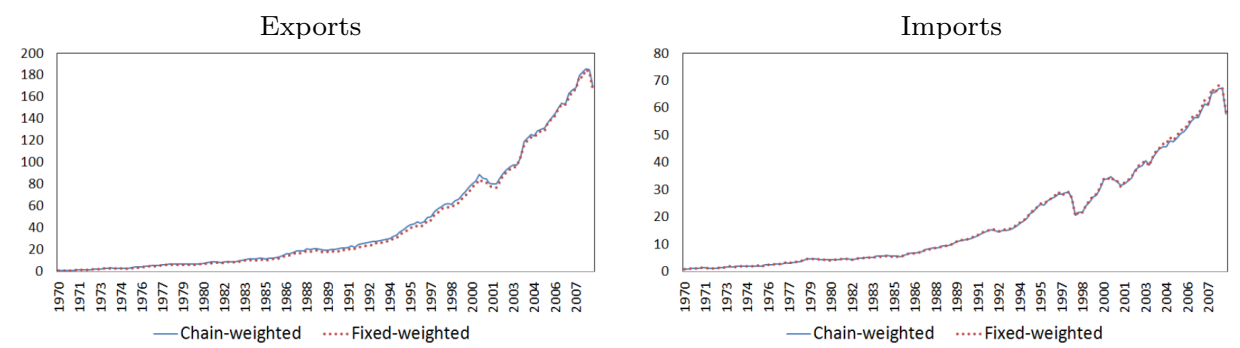

Figure 2.3. Comparison of alternative measures, by selected economic activity \& expenditure 
Table 3.1. Filtering methods

\begin{tabular}{cccccc}
\hline & \multicolumn{2}{c}{ Sequential } & & \multicolumn{2}{c}{ Direct } \\
\cline { 2 - 3 } & H-HP & MA-HP & D-HP & CF \\
\hline Smoothing & Henderson MA (7q.) & Simple MA (3q.) & & $\lambda_{L}=0.5$ & $p_{l}=5$ \\
De-trending & HP $(\lambda=215)$ & HP $(\lambda=215)$ & & $\lambda_{U}=215$ & $p_{u}=24$ \\
\hline
\end{tabular}

Table 3.2. Rating of filtering methods

\begin{tabular}{lllll}
\hline & H-HP & MA-HP & D-HP & CF \\
\hline MAR $^{1)}$ & $2(0.71)$ & $3(0.72)$ & $\mathbf{1}(\mathbf{0 . 5 4})$ & $4(0.73)$ \\
Sign Change $^{2)}, \%$ & $4(37.7)$ & $3(36.3)$ & $\mathbf{1 ( 2 5 . 0 )}$ & $2(33.7)$ \\
Direction Change $^{3)}, \%$ & $3(46.9)$ & $4(47.2)$ & $\mathbf{1}(\mathbf{1 5 . 1})$ & $2(25.0)$ \\
Detecting Turning Points $^{4)}$ & $3(+1.5)$ & $1(+1.2)$ & $\mathbf{2 ( + 1 . 3 )}$ & $4(+2.3)$ \\
\hline
\end{tabular}

Notes: 1) MAR(Mean Absolute Revision): $\sum_{t}\left|R_{i, t}\right| / n$, where $R_{i, t}$ is the $h$ revision of observation $t$, and $\widehat{C}_{t, t+i}$ is the estimate of the cyclical component for $t$ by using the information up to $t+i$.

2) Sign Change: $\sharp\left[\operatorname{sign}\left(\widehat{C}_{t, t}-100\right) \neq \operatorname{sign}\left(\widehat{C}_{t, t+1}-100\right)\right] / n$

3) Direction Change: $\sharp\left[\operatorname{sign}\left(\widehat{C}_{t, t}-\widehat{C}_{t-1, t}\right) \neq \operatorname{sign}\left(\widehat{C}_{t, t+1}-\widehat{C}_{t-1, t+i}\right)\right] / n$

4) Detecting Turning Points: $\widehat{T}-T, \widehat{T}: 1^{\text {st }}$ appearances of peaks or troughs while adding new observations successively, T: Turning points (1970-2009)

성격을 규정하고 있다. 다양한 경제지표들의 순환변동과 관련한 주요 이슈에는 변동성의 정도, 변동 의 지속성 및 다른 경제지표와의 대응성 등이 있다. 여기서는 우리나라의 1970.1/4 2008.4/4분기 중 의 실질GDP와 그 구성항목을 추세치와 순환변동치로 구분하여 살펴봄으로써 연쇄 실질GDP와 기존 의 고정 실질 $\mathrm{GDP}$ 를 경기순환 및 대응성 측면에서 비교 검정해 보고자 한다. 계절조정 $(\mathrm{SA})$ 국민소득 통계는 추세변동 $(\mathrm{T})$, 순환변동 $(\mathrm{C})$, 불규칙변동(I)으로 구성되어 있다. 순환변동치를 추출하는 방법에는 여러가지 방법이 있는데 계절조정계열로부터 불규칙변동과 추세변동을 순차적으로 제거하는 단계적 추 출법과 순환변동을 직접 추출하는 직접추출법으로 크게 나눌 수 있다. 단계적 추출법에는 불규칙변동 제거방법으로 단순이동평균법과 헨더슨이동평균법, LOESS, 칼만필터(Kalman filtering), 평활스플라 인(smoothing spline) 등의 다양한 방법들이 있다. 추세변동을 제거하는 방법에는 회귀분석법, 국면평 균법(PAT), Beveridge and Nelson법 및 $\mathrm{HP}$ 필터가 주로 이용되고 있다. 직접 추출법으로는 구간통과 필터 방법인 Baxter-King 필터와 Christiano-Fitzgerald 필터 및 Double-HP 필터를 들 수 있다.

Nilsson과 Gyomai (2008)는 $\mathrm{OECD}$ 의 경기선행지수 순환변동치 추출방법에 대한 연구결과 국면전 환점 포착능력에서는 $\mathrm{D}-\mathrm{HP}$ 필터 사용을 수정폭 측면에서는 $\mathrm{CF}$ 필터가 우수한 것으로 평가하고 있다. $\mathrm{OECD}$ 는 국면전환점 포착 능력에 주안점을 두어 2008 년 12 월부터 경기선행종합지수 순환변동치 추출 에 D-HP필터를 도입하였다. Jung과 Yeon (2011)는 1970.1/4 2009.4/4분기 중 우리나라 계절조정 연 쇄 GDP에 H-HP필터(헨더슨 $+\mathrm{HP}$ ), MA-HP필터(단순중심이동평균 $+\mathrm{HP}$ ), D-HP필터, $\mathrm{CF}$ 필터 등 4 가 지 방법을 이용하여 순환변동치를 추출한 후 순환변동치의 안정성과 신뢰성을 평가하였다. 동 연구에서 사용된 D-HP의 평활화 모수값 $\lambda_{L}, \lambda_{U}$ 는 우리나라의 경기순환주기를 최소 5 분기와 최대 24 분기로 보 고 이에 해당하는 0.5 와 215 로 정하였다 (Table 3.1).

동 연구에서 신규자료 추가에 따른 순환변동치 수정폭, 자료추가에 따른 국면변화의 안정성, 순환변동치 의 전기대비 방향의 신뢰성, 국면전환점 포착능력 등 4 가지 평가기준을 적용하여 평가한 결과 D-HP필 터가 수정폭, 위치의 안정성, 방향의 신뢰성 등 3 개 기준에서 가장 우월하고 실시간 국면전환점 포착 능 력 면에서는 MA-HP 다음으로 우월한 것으로 밝히고 있다 (Table 3.2). 이에 근거하여 본 연구에서는 $\mathrm{D}-\mathrm{HP}$ 필터를 이용하여 순환변동치를 추출하고자 한다. 

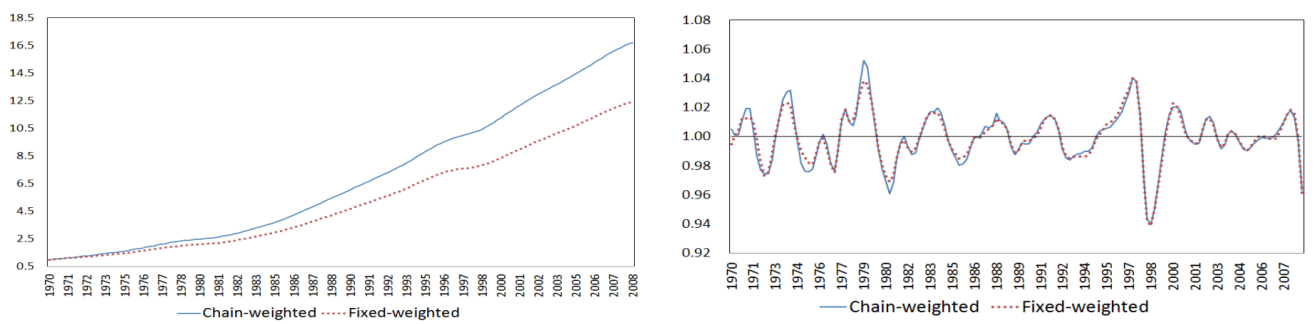

Figure 3.1. Comparison of trends and cycles of GDP

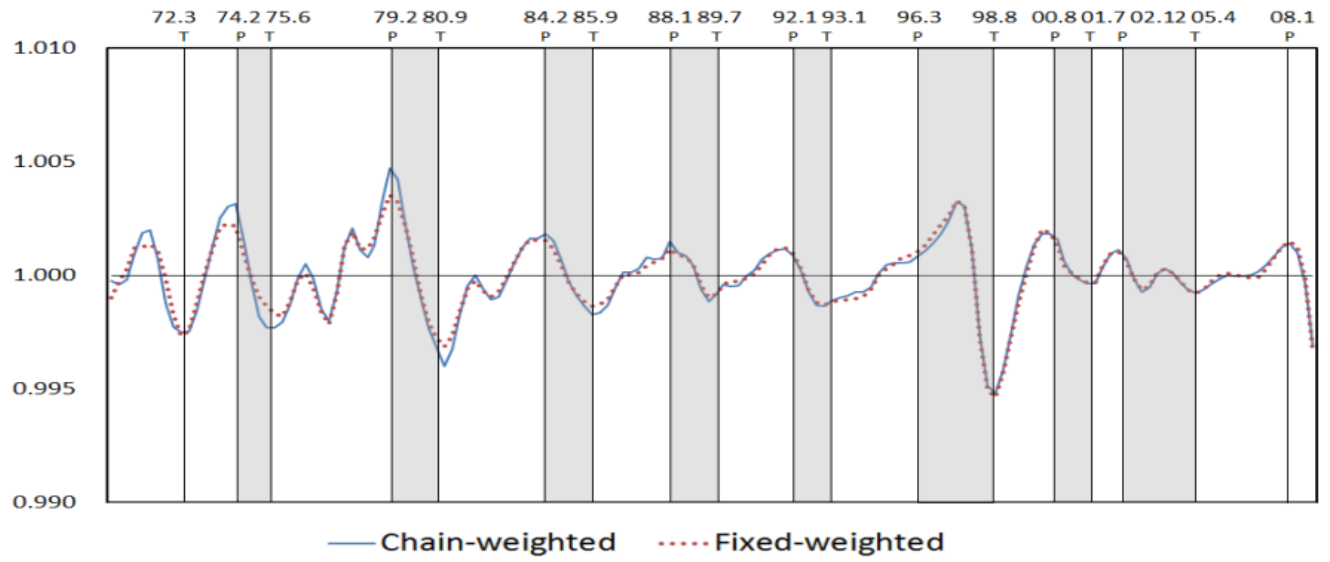

Figure 3.2. Comparison of business cycle reference dates and GDP cycles

\section{2. 추세와 순환변동}

1970.1/4 2008.4/4분기 중 연쇄가중법 도입에 따라 GDP의 추세가 고정가중법에 의한 추세보다 높아 진 반면 순환변동에 미치는 영향은 높지 않은 것으로 나타났다. 따라서 고정가중법에서 대체편의 등으 로 과대 또는 과소평가되었던 효과는 연쇄가중법 도입으로 대부분이 추세치를 보정해주는 것으로 보인 다 (Figure 3.1).

우리나라의 GDP와 그 구성항목의 순환변동치를 추출해 봄으로써 연쇄GDP와 기존 고정 GDP의 경기 순환 특성을 비교 검정해 보고자 한다. 우선 저점은 연쇄 GDP의 순환변동치는 기준순환주기보다 3 개 분기가 1 분기씩 후행하고 2 개 분기는 1 분기씩 선행한다. 고정 GDP 순환변동치는 2 개 분기에서 1 분기 씩 후행하고 3 개 분기에서 1 분기씩 선행한다.

한편 정점에서는 연쇄 GDP 순환변동치가 기준순환일보다 1 개 분기에서 5 분기 후행하고 3 개 분기에서 1 분기씩 선행한다. 고정 GDP는 1 개 분기에서 5 분기 후행하고 3 개 분기에서 1 분기씩, 2 개 분기에서 2 분기씩 선행함으로써 연쇄 GDP 순환변동치가 보다 더 일치하는 모습을 보이고 있다 (Figure 3.2 , Table 3.3). 따라서 연쇄가중 경제성장률을 도입한 이후 경기순환변동치가 기준순환과 보다 더 일치하고 $\mathrm{GDP}$ 통계가 가지고 있는 고유한 성질이 훼손되지 않는 것으로 판단할 수 있다.

이외에도 주요 4 개 경제활동별 부가가치의 순환변동치를 보면 대체로 차이가 없어 보인다. 민간소비, 정부소비, 건설투자, 설비투자, 수출, 수입 등 6 개 지출항목에 대한 순환변동치의 경우 구간별로 보면 정 부소비, 건설투자, 수입항목에서는 연쇄가중성장률과 고정가중성장률 간에 다소 상이한 움직임을 보이 
Table 3.3. Time lag between GDP cycle and business cycle reference dates

(Quarter)

\begin{tabular}{|c|c|c|c|c|c|c|c|}
\hline \multicolumn{2}{|c|}{ Chain GDP Cycle } & \multicolumn{2}{|c|}{ Fixed GDP Cycle } & \multicolumn{2}{|c|}{ Business-Chain } & \multicolumn{2}{|c|}{ Business-Fixed } \\
\hline Trough & Peak & Trough & Peak & Trough & Peak & Trough & Peak \\
\hline $72.2 / 4$ & $74.1 / 4$ & $72.2 / 4$ & $73.4 / 4$ & -1 & 0 & -1 & 1 \\
\hline $75.1 / 4$ & $79.1 / 4$ & $75.3 / 4$ & $79.1 / 4$ & 1 & 0 & -1 & 0 \\
\hline $80.4 / 4$ & $84.1 / 4$ & $80.4 / 4$ & $83.3 / 4$ & -1 & 0 & -1 & 2 \\
\hline $85.3 / 4$ & $88.1 / 4$ & $85.3 / 4$ & $88.1 / 4$ & 0 & 0 & 0 & 0 \\
\hline $89.2 / 4$ & $91.4 / 4$ & $89.2 / 4$ & $91.4 / 4$ & 1 & 1 & 1 & 1 \\
\hline $93.1 / 4$ & $97.2 / 4$ & $93.1 / 4$ & $97.2 / 4$ & 0 & -5 & 0 & -5 \\
\hline $98.3 / 4$ & $00.2 / 4$ & $98.3 / 4$ & $00.1 / 4$ & 0 & 1 & 0 & 2 \\
\hline $01.3 / 4$ & $02.3 / 4$ & $01.3 / 4$ & $02.3 / 4$ & 0 & 1 & 0 & 1 \\
\hline 05.1 .4 & $08.1 / 4$ & $05.1 / 4$ & $08.1 / 4$ & 1 & 0 & 1 & 0 \\
\hline
\end{tabular}

는 기간도 있는 것으로 나타나고 있으나 6개 항목 모두 대체로 차이는 없는 것으로 보인다 (Figure 3.3). 한편 GDP 순환변동치와 주요 구성항목의 순환변동치간 교차상관분석결과 방법론 변화가 경기변동관계 에 유의한 영향을 미치지는 않는 것으로 나타났다 (Table 3.4). 즉 연쇄가중 경제성장률을 도입한 후에 도 $\mathrm{GDP}$ 와 경제활동별 부가가치들 간의 관계를 특징짓는 경험적 규칙성에 차이가 없으며, GDP와 지출 항목과의 관계에도 차이가 없는 것으로 판단된다.

\section{3. $\mathrm{GDP}$ 의 경기대응성}

우리나라 경기순환을 공식적으로 나타내 주는 경기종합지수 및 6 개 구성내역의 순환변동치를 이용하여 실질GDP 순환변동치와의 상관분석을 실시해 봄으로써 고정 GDP를 연쇄 GDP로 대체하는 경우 경기대 응성에 차이가 있는지를 알아보기로 한다. Table 3.5 에서 경기종합지수 순환변동치와 연쇄GDP의 순환 변동치간의 교차상관계수는 0.96 으로 경기종합지수와 고정 $\mathrm{GDP}$ 의 순환변동치간의 상관계수와 비슷한 값을 보이고 있고 동일성 검정결과 유의한 차이는 없는 것으로 나타났다. 비농림어업취업자수 등 6 개 구성항목 순환변동치들과 $\mathrm{GDP}$ 순환변동치간의 상관관계에 있어서도 두 방법 간에 유의한 차이는 보이 지 않고 있다.

\section{4. 결론}

국민소득통계가 경제현실을 정확히 포착하도록 편제하는 것은 국민소득통계 작성자들에게는 커다란 과 제이다. 과거 기술혁신이 느리고 상품의 출현 및 퇴출도 빠르지 않았던 시기에는 고정가중법에 의해서 도 경제현실을 잘 반영하는 경제성장률의 측정이 가능하였다. 그러나 최근에 이르러 기술혁신이 급격히 진행되고 새로운 상품의 출현과 퇴출이 신속히 일어나는 경제현실에서는 고정가중 경제성장률을 작성 하는 경우 '대체편의'와 주기적으로 반복되는 '시계열 전면재수정'의 문제점이 노정되어 있었다. UN은 이 두 가지 문제를 동시에 해결해 줄 수 있는 연쇄가중 경제성장률을 주도적으로 개발하여 각국으로 하 여금 이를 도입하도록 권고하였다. 한국은행은 2009 년에 2005 년 기준년을 개편하면서 연쇄가중 경제성 장률을 작성 공표하였다. 그 결과 1970 1999년 중에는 연쇄가중 경제성장률이 기존의 고정가중 경제 성장률보다 높게 나타났으나 2000 2008년 중에는 연평균 $0.1 \%$ p 낮게 나타나 전체적으로는 $0.8 \% \mathrm{p}$ 높 게 나타났다. 한편 분기 연쇄가중 전기비 경제성장률은 분석대상 기간중 고정가중 경제성장률보다 평 균 $0.19 \%$ 높게 나타났으며 구간별로도 상당한 차이를 보이고 있다. 본고에서는 이러한 외견상의 차이 가 $\mathrm{GDP}$ 의 경기적 특성에 변화를 가져오는지를 알아보기 위해 추세선과 순환변동치를 추출하여 보았다. 첫째로 추세선이 변하여 장기적인 잠재성장률에 영향을 미치는 것으로 나타났다. 둘째로 순환변동치는 
(Economic Activity)
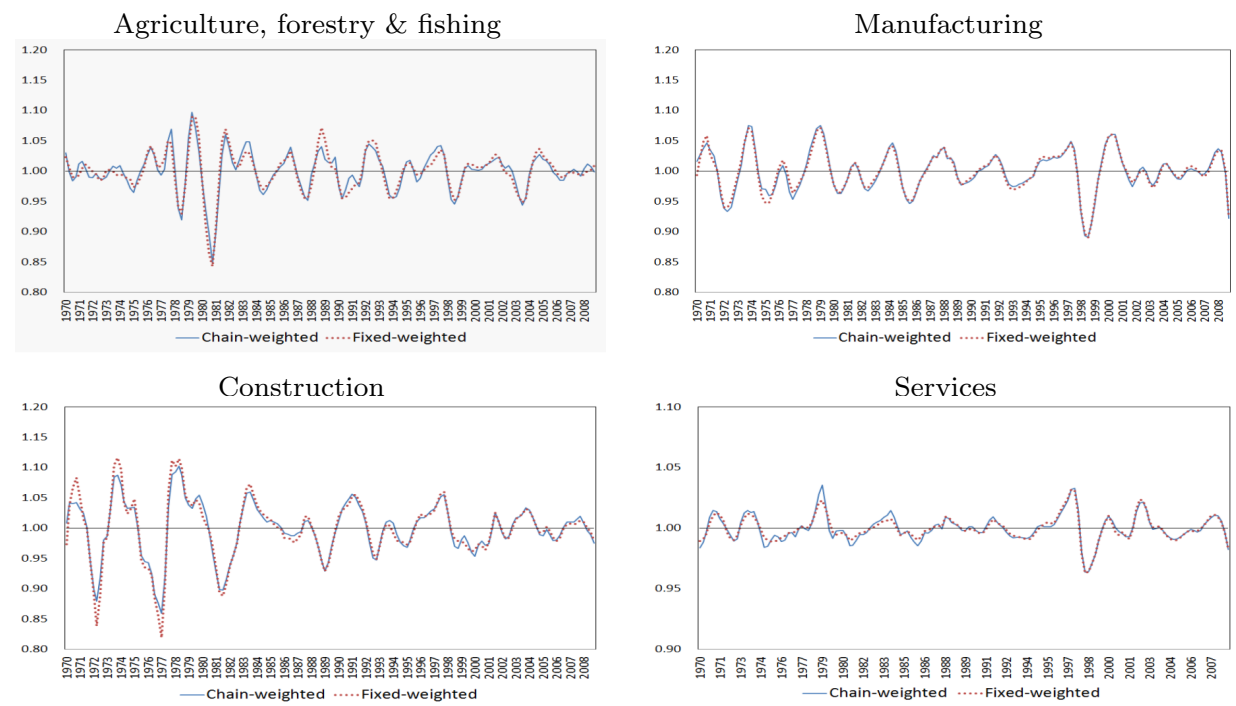

(Expenditure)
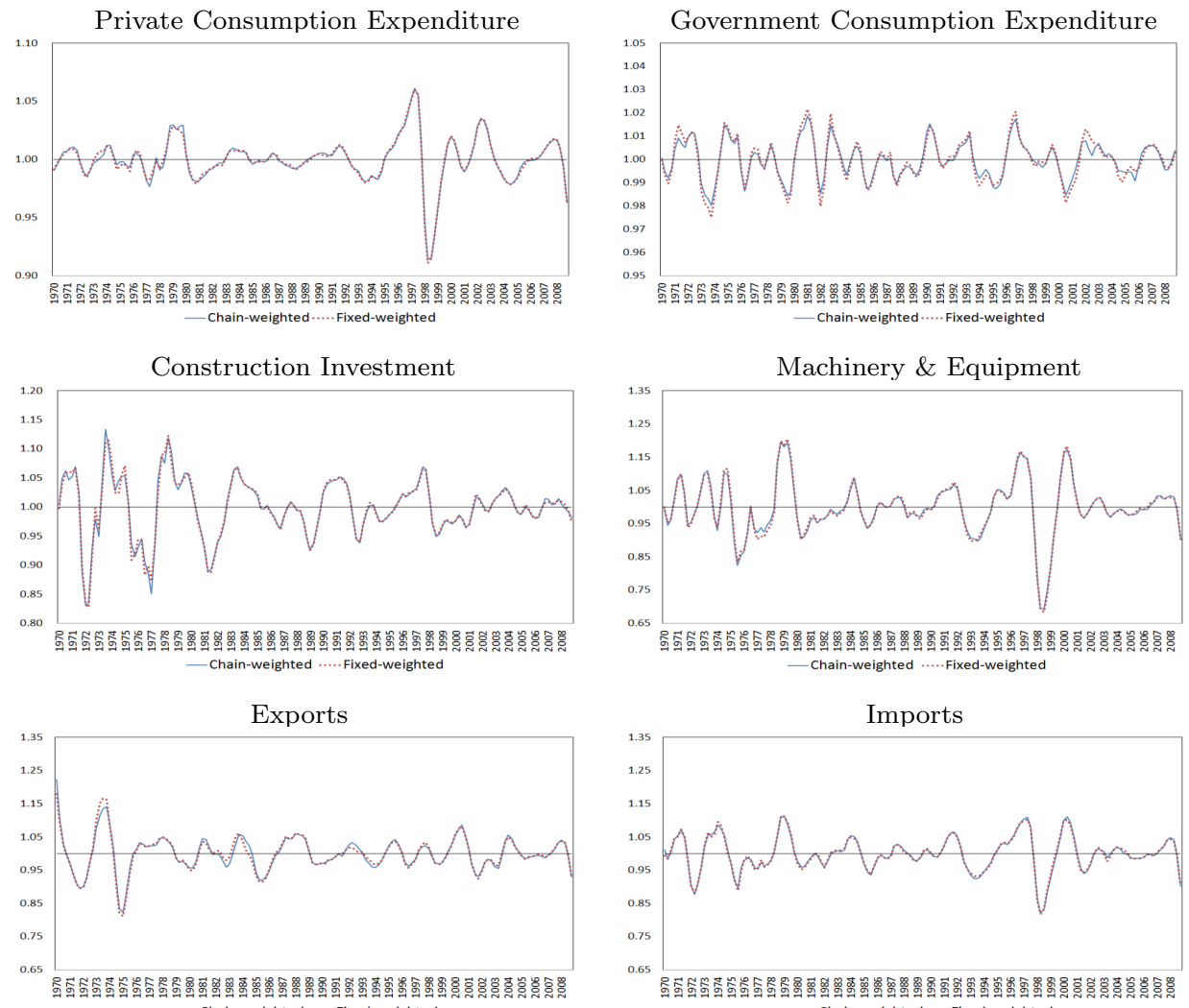

Figure 3.3. Comparison of cycles of selected components of GDP 
Table 3.4. Cross-correlation coefficients of GDP cycle with component cycle

\begin{tabular}{|c|c|c|c|c|c|c|c|c|c|c|}
\hline & & \multicolumn{9}{|c|}{ Cross-Correlations with GDP $(t+j)$} \\
\hline & & 8 & 4 & 2 & 1 & 0 & -1 & -2 & -4 & -8 \\
\hline \multicolumn{11}{|c|}{ (Economic Activity) } \\
\hline \multirow{3}{*}{ GDP } & Chain-weighted & & & & & & 0.984 & 0.965 & 0.925 & 0.848 \\
\hline & Fixed-weighted & & & & & & 0.983 & 0.964 & 0.924 & 0.846 \\
\hline & $p$-value & & & & & & 0.789 & 0.900 & 0.952 & 0.951 \\
\hline \multirow{3}{*}{$\begin{array}{l}\text { Agriculture, } \\
\text { Forestry } \\
\text { \& Fishing }\end{array}$} & Chain-weighted & 0.048 & -0.138 & 0.071 & 0.300 & 0.460 & 0.412 & 0.201 & -0.186 & -0.175 \\
\hline & Fixed-weighted & 0.111 & -0.147 & 0.035 & 0.214 & 0.336 & 0.329 & 0.192 & -0.143 & -0.158 \\
\hline & $p$-value & 0.577 & 0.936 & 0.750 & 0.420 & 0.194 & 0.399 & 0.941 & 0.699 & 0.883 \\
\hline \multirow{3}{*}{ Manufacturing } & Chain-weighted & -0.397 & -0.142 & 0.499 & 0.781 & 0.902 & 0.736 & 0.426 & -0.224 & -0.361 \\
\hline & Fixed-weighted & -0.333 & -0.069 & 0.518 & 0.772 & 0.880 & 0.698 & 0.386 & -0.257 & -0.400 \\
\hline & $p$-value & 0.515 & 0.517 & 0.827 & 0.845 & 0.341 & 0.493 & 0.671 & 0.754 & 0.693 \\
\hline \multirow{3}{*}{ Construction } & Chain-weighted & -0.565 & -0.039 & 0.279 & 0.419 & 0.504 & 0.490 & 0.403 & 0.178 & -0.151 \\
\hline & Fixed-weighted & -0.521 & -0.045 & 0.273 & 0.426 & 0.514 & 0.474 & 0.364 & 0.152 & -0.136 \\
\hline & $p$-value & 0.584 & 0.958 & 0.958 & 0.936 & 0.907 & 0.858 & 0.689 & 0.821 & 0.894 \\
\hline \multirow{3}{*}{ Services } & Chain-weighted & -0.345 & -0.200 & 0.458 & 0.744 & 0.856 & 0.704 & 0.433 & -0.042 & -0.303 \\
\hline & Fixed-weighted & -0.342 & -0.185 & 0.468 & 0.756 & 0.879 & 0.733 & 0.467 & -0.050 & -0.280 \\
\hline & $p$-value & 0.983 & 0.889 & 0.905 & 0.810 & 0.430 & 0.602 & 0.706 & 0.939 & 0.822 \\
\hline \multicolumn{11}{|c|}{ (Expenditure) } \\
\hline \multirow{3}{*}{$\begin{array}{c}\text { Private } \\
\text { Consumption }\end{array}$} & Chain-weighted & -0.345 & -0.206 & 0.373 & 0.649 & 0.786 & 0.680 & 0.446 & -0.047 & -0.195 \\
\hline & Fixed-weighted & -0.368 & -0.159 & 0.439 & 0.716 & 0.850 & 0.713 & 0.449 & -0.073 & -0.240 \\
\hline & $p$-value & 0.823 & 0.676 & 0.488 & 0.268 & 0.089 & 0.566 & 0.974 & 0.819 & 0.683 \\
\hline \multirow{3}{*}{$\begin{array}{l}\text { Government } \\
\text { Consumption }\end{array}$} & Chain-weighted & -0.172 & 0.064 & -0.040 & -0.168 & -0.262 & -0.262 & -0.165 & 0.157 & 0.247 \\
\hline & Fixed-weighted & -0.173 & 0.013 & -0.006 & -0.095 & -0.182 & -0.193 & -0.116 & 0.142 & 0.233 \\
\hline & $p$-value & 0.990 & 0.654 & 0.765 & 0.513 & 0.461 & 0.525 & 0.660 & 0.893 & 0.896 \\
\hline \multirow{3}{*}{ Construction } & Chain-weighted & -0.540 & -0.067 & 0.297 & 0.459 & 0.551 & 0.526 & 0.413 & 0.134 & -0.189 \\
\hline & Fixed-weighted & -0.511 & -0.059 & 0.302 & 0.468 & 0.557 & 0.510 & 0.389 & 0.119 & -0.157 \\
\hline & $p$-value & 0.721 & 0.946 & 0.968 & 0.918 & 0.942 & 0.846 & 0.808 & 0.897 & 0.774 \\
\hline \multirow{3}{*}{$\begin{array}{c}\text { Machinery \& } \\
\text { Equipment }\end{array}$} & Chain-weighted & -0.416 & -0.029 & 0.502 & 0.700 & 0.770 & 0.653 & 0.433 & -0.072 & -0.399 \\
\hline & Fixed-weighted & -0.427 & -0.025 & 0.516 & 0.718 & 0.790 & 0.669 & 0.443 & -0.070 & -0.437 \\
\hline & $p$-value & 0.912 & 0.972 & 0.870 & 0.756 & 0.650 & 0.799 & 0.914 & 0.982 & 0.689 \\
\hline \multirow{3}{*}{ Exports } & Chain-weighted & -0.095 & 0.088 & 0.312 & 0.388 & 0.398 & 0.263 & 0.062 & -0.331 & -0.178 \\
\hline & Fixed-weighted & -0.042 & 0.100 & 0.293 & 0.357 & 0.354 & 0.228 & 0.040 & -0.340 & -0.188 \\
\hline & $p$-value & 0.638 & 0.914 & 0.859 & 0.754 & 0.652 & 0.747 & 0.846 & 0.925 & 0.925 \\
\hline \multirow{3}{*}{ Imports } & Chain-weighted & -0.414 & -0.169 & 0.496 & 0.766 & 0.867 & 0.714 & 0.439 & -0.134 & -0.407 \\
\hline & Fixed-weighted & -0.414 & -0.113 & 0.538 & 0.798 & 0.880 & 0.697 & 0.404 & -0.165 & -0.417 \\
\hline & $p$-value & 0.997 & 0.617 & 0.613 & 0.481 & 0.650 & 0.767 & 0.710 & 0.785 & 0.916 \\
\hline
\end{tabular}

고정GDP와 연쇄 GDP간 통계적으로 유의한 차이를 보이지 않아 GDP의 경기적 특성에는 차이가 없는 것으로 나타났다. 셋째 GDP 순환변동치와 경기종합지수 구성항목 순환변동치간의 대응성을 분석해본 결과 통계적으로 유의한 차이는 보이지 않는 것으로 나타났다. 따라서 연쇄가중 경제성장률 도입으로 인한 경제성장률의 차이는 잠재성장률에는 영향을 미치나 $\mathrm{GDP}$ 의 경기적 특성에는 영향을 미치지 않는 것으로 결론내릴 수 있다. 
Table 3.5. Cross-correlations of GDP cycle with cyclical components of composite index

\begin{tabular}{|c|c|c|c|c|c|c|c|c|c|c|}
\hline & & \multicolumn{9}{|c|}{ Cross-Correlations with GDP $(t+j)$} \\
\hline & & 8 & 4 & 2 & 1 & 0 & -1 & -2 & -4 & -8 \\
\hline Cyclical & Chain-weighted & -0.450 & -0.217 & 0.463 & 0.792 & 0.964 & 0.803 & 0.469 & -0.261 & -0.351 \\
\hline Component of & Fixed-weighted & -0.438 & -0.197 & 0.469 & 0.792 & 0.965 & 0.802 & 0.474 & -0.257 & -0.383 \\
\hline Coincident Index & $p$-value & 0.942 & 0.915 & 0.971 & 1.000 & 0.901 & 0.987 & 0.975 & 0.982 & 0.846 \\
\hline \multirow{3}{*}{$\begin{array}{l}\text { Number of } \\
\text { Employees }\end{array}$} & Chain-weighted & -0.294 & -0.484 & 0.176 & 0.570 & 0.852 & 0.881 & 0.703 & 0.068 & -0.415 \\
\hline & Fixed-weighted & -0.295 & -0.465 & 0.183 & 0.575 & 0.860 & 0.886 & 0.713 & 0.087 & -0.451 \\
\hline & $p$-value & 0.997 & 0.897 & 0.967 & 0.968 & 0.884 & 0.909 & 0.919 & 0.922 & 0.822 \\
\hline Industrial & Chain-weighted & -0.256 & -0.153 & 0.402 & 0.722 & 0.912 & 0.748 & 0.399 & -0.379 & -0.512 \\
\hline Production & Fixed-weighted & -0.250 & -0.134 & 0.405 & 0.717 & 0.904 & 0.734 & 0.392 & -0.381 & -0.533 \\
\hline & $p$-value & 0.973 & 0.920 & 0.985 & 0.960 & 0.801 & 0.872 & 0.966 & 0.989 & 0.878 \\
\hline \multirow{3}{*}{$\begin{array}{l}\text { Retail Sales } \\
\text { Index }\end{array}$} & Chain-weighted & -0.541 & 0.099 & 0.617 & 0.786 & 0.815 & 0.585 & 0.258 & -0.339 & -0.238 \\
\hline & Fixed-weighted & -0.524 & 0.107 & 0.619 & 0.788 & 0.823 & 0.594 & 0.265 & -0.353 & -0.271 \\
\hline & $p$-value & 0.906 & 0.965 & 0.984 & 0.975 & 0.893 & 0.946 & 0.972 & 0.933 & 0.857 \\
\hline Shipment & Chain-weighted & -0.473 & 0.079 & 0.632 & 0.835 & 0.892 & 0.646 & 0.272 & -0.461 & -0.381 \\
\hline Index for & Fixed-weighted & -0.455 & 0.093 & 0.634 & 0.834 & 0.891 & 0.639 & 0.267 & -0.471 & -0.410 \\
\hline Domestic Market & $p$-value & 0.909 & 0.945 & 0.985 & 0.981 & 0.978 & 0.948 & 0.979 & 0.949 & 0.860 \\
\hline \multirow{3}{*}{ Imports } & Chain-weighted & -0.403 & -0.256 & 0.399 & 0.713 & 0.876 & 0.799 & 0.526 & -0.201 & -0.526 \\
\hline & Fixed-weighted & -0.398 & -0.233 & 0.402 & 0.711 & 0.878 & 0.801 & 0.533 & -0.188 & -0.558 \\
\hline & $p$-value & 0.976 & 0.902 & 0.985 & 0.984 & 0.963 & 0.983 & 0.958 & 0.947 & 0.814 \\
\hline \multirow{3}{*}{$\begin{array}{l}\text { Index of } \\
\text { Services }\end{array}$} & Chain-weighted & -0.105 & -0.282 & 0.153 & 0.435 & 0.583 & 0.315 & 0.042 & -0.209 & 0.188 \\
\hline & Fixed-weighted & -0.077 & -0.273 & 0.141 & 0.419 & 0.569 & 0.290 & 0.021 & -0.224 & 0.190 \\
\hline & $p$-value & 0.908 & 0.969 & 0.963 & 0.937 & 0.932 & 0.911 & 0.934 & 0.950 & 0.993 \\
\hline
\end{tabular}

Notes : 1) Excluding Value of Construction Completed

2) $H_{0}: \rho_{i}=\rho_{j}$, Test statistics $Z=\sqrt{n-3} /(2 \sqrt{2})\left[\ln \left\{\left(1+\rho_{i}\right) /\left(1-\rho_{i}\right)\right\}-\ln \left\{\left(1+\rho_{j}\right) /\left(1-\rho_{j}\right)\right\}\right]$ ( $\rho_{i}=$ Cross-Correlations with Fixed-Weighted GDP and $\rho_{j}=$ Cross-Correlations with ChainWeighted GDP)

\section{References}

Bank of Korea (2009). Understanding of Chain-Weighted GDP, Seoul

Deaton, A. and Muellbauer, J. (1980). Economic and Consumer Behavior, Cambridge University Press, Cambridge.

Jung, H. and Yeon, S. (2011). Growth Cycle Analysis by Double-HP Filtering, Fall 2011 Korea Statistical Association Meeting.

Newey, W. K. and West, K. D. (1987). A simple, positive semi-definite, heteroskedasticity and autocorrelation consistent covariance matrix, Econometrica, 55, 703-708.

Nilsson, R. and Gyomai, G. (2008). Cycle Extraction, Staff Papers, OECD.

Pakko, M. R. (1997). The Business Cycle and Chain-weighted GDP: Has Our Perspective Changed?, Federal Reserve Bank of St. Louis Review, 79, 39-49.

Parker, R. P. and Seskin, E. P (1996). Improved estimates of the national income and product accounts for 1959-95: Results of the comprehensive revision, Survey of Current Business, 76, 1-31.

Pesaran, M. H. and Timmerman, A. G. (1992). A simple non parametric test of predictive performance, Journal of Business and Economic Statistics, 10, 461-465.

Steindel, C. (1995). Chain-weighting: The new approach to measuring GDP, Current Issues in Economics and Finance, 1, 1-5.

Young, A. H. (1993). Alternative measures of change in real output and prices, quarterly estimates for 1959-92, Survey of Current Business, 73, 31-41. 